\title{
Oil Content and Fatty Acids Composition during Seeds Storage of Two Ecotypes of Jatropha curcas L. from Mali
}

\author{
Hamidou SENOU ${ }^{1,2}$, Cai Xia ZHENG ${ }^{1, *}$, Mamadou Bado TRAORE ${ }^{1}$, Boubale SISSOKO ${ }^{2}$, \\ Maurice KAMATE ${ }^{3}$, Ousmane NIANGALY ${ }^{2}$ \\ ${ }^{1}$ College of Biological Sciences and Biotechnology, Beijing Forestry University, Beijing 100083, P. R. China \\ ${ }^{2}$ Institut Polytechnique Rural de formation et de Recherche Appliquée (IPR/IFRA), Katibougou Bp: 06, Koulikoro, Mali \\ ${ }^{3}$ Centre de Teriya Bugu, BP : 596, Segou, Mali \\ *Corresponding author: zhengcx@bjfu.edu.cn
}

\begin{abstract}
To study the oil contents and fatty acid composition among the samples of Jatropha curcas L. from Mali, the seeds were collected from Katibougou (ecotype I) and Teriyabougou (ecotype II) center. Soxhlet extraction methods were used to determine the oil content of J. curcas seeds. Two different periods were used for various analyses and each analysis was duplicated. The oil concentration ranged in the first and second time of extraction from $62.95 \pm 0.24 \%$ to $61.11 \pm .18 \%$ (ecotype I) and $65.9 \pm 0.76 \%$ to $65.06 \pm 0.36 \%$ (ecotype II) respectively. The fatty acid profiles were developed by gas chromatography-mass spectrometry (GC-MS). Sixteen fatty acids were identified in quantifiable amount in the seed oils. Among these, saturated and unsaturated fatty acids were obtained with a predominance of unsaturated fatty acids. The oleic acid and linoleic acid were the dominant fatty acids present in the $J$. curcas seed oil of Mali. Their ratio (Oleic/Linoleic) varies from $0.87 \pm 0.02 \%$ to $1.22 \pm 0.02 \%$ (ecotype I) and $0.82 \pm 0.06 \%$ to $1.13 \pm 0.11 \%$ (ecotype II). This ratio possesses a high level of methyl oleate (monounsaturated fatty acid) which might have an excellent effect on biodiesel properties.
\end{abstract}

Keywords: Jatropha curcas, seed oils, fatty acids, GC-MS, Mali

Cite This Article: Hamidou SENOU, Cai Xia ZHENG, Mamadou Bado TRAORE, Boubale SISSOKO, Maurice KAMATE, and Ousmane NIANGALY, "Oil Content and Fatty Acids Composition during Seeds Storage of Two Ecotypes of Jatropha curcas L. from Mali." Research in Plant Sciences, vol. 5, no. 1 (2017): 9-14. doi: 10.12691/plant-5-1-2.

\section{Introduction}

Jatropha curcas L. (Family: Euphorbiaceae), is considered to be a promising source of non-edible oil that can be used as a feedstock for the production of biodiesel. Native to central America and Mexico, J. curcas was spread by Portuguese seafarers via the Cape Verde and guinea-Bissau to other countries in Africa and Asia [1].

$J$. curcas is currently found in almost all tropical and sub-tropical regions in the world. Jatropha tolerates drought very well and can survive on moisture in the air. It can also survive up to 50 years. J. curcas oil is used in soap production, for the lighting in households, cosmetic industry and also for medicinal purposes.

At present it is one of the most highly promoted seed oil plants in the world. Its seeds have about 30 to $40 \%$ of oil contents which varies depending on the ecotype $[2,3,4]$.

Today, J. curcas has gained much attention and has become a very interesting crop for both none oil producing and oil producing countries around the world [2]. African countries such as Mali have been extracting $J$. curcas seed oil for years.

In a Mali GTZ project found $J$. curcas seed oil as an economic substitute for diesel in several remote villages, especially with some amendments to conventional diesel engines. [2]

This oil is also used as a feedstock for biodiesel production $[5,6]$. For biodiesel introduction on a large scale, it is required to do some description of quality requirements in a standard manner, because the chemical structure of fatty acid methyl esters are older than fossil diesel fuels [7]. The oil from $J$. curcas has properties which are lower in quality, for diesel, in its energy content, flash point, and solidifying point. It is also more viscous and has a poorer ignition quality than diesel. Trans esterification of the plant oil reduces the viscosity of the oil to a range of $4-5 \mathrm{~mm}^{2} / \mathrm{s}$ closer to that of mineral diesel and hence improves combustion, and the fatty acid methyl esters are formed which can also be used as biodiesel $[8,9,10]$.

The aim of this study was to determine the variation in oil content and fatty acid composition of seeds from two different ecotype of Mali during their storage periods, in order to find solutions for the problems of biodiesel production in Mali such as the seed conservation and oil storage until transesterification.

\section{Materials and Methods}

\subsection{Plant Materials}

$J$. curcas seeds were collected from two centers; Teriyabugu (EcotypeI) and the Rural Polytechnic Institute 
for Training and Applied Research (IPR/IFRA) of Katibougou (EcotypeII) in 2014. The seeds were stored at room temperature of $30 \pm 5^{\circ} \mathrm{C}$ before use. Two dates (D1 and D2) were used for the different analysis. D1 and D2 were a period of six and nine months of seed storage respectively. The ripe seeds were collected from the different site and the damaged seeds were discarded. The seed kernels were ground to powder using a grinder prior to oil extraction.

\subsection{Oil Extraction}

$5 \mathrm{~g}$ of the ground seeds were taken and were placed in the Soxhlet apparatus and the oil was extracted using hexane as solvent. The extraction was carried out in a boiling hot water bath for $3 \mathrm{~h}$ with $180 \mathrm{ml}$ of $n$-hexane at $80^{\circ} \mathrm{C}$. The solvent was then transferred to a desiccator and allowed to cool. The solvent was evaporated in a rotary evaporator with a control water temperature at $35^{\circ} \mathrm{C}$. The amount of oil content was determined as a percentage of total oil present in $J$. curcas seed kernels. The extraction was run in duplicate and then the means and the standard deviations were calculated. The oil obtained was stored at $4^{\circ} \mathrm{C}$ before the other analysis.

\subsection{GC condition for Analysis of Fatty Acid Composition}

About two drops of sample oils were converted to methyl ester using $0.5 \mathrm{ml} 2 \mathrm{~N} \mathrm{KOH}$ in methyl alcohol, in $1.5 \mathrm{ml} \mathrm{n}$-hexane. After each addition of solution the sample was mixed by using vortexed for $2 \mathrm{~min}$. Then the supernatant of the top layer containing methyl ester was extracted for GC injection. The fatty acid methyl esters were identified by gas chromatography coupled with mass spectrometry (GC/MS QP2010 Shimadzu, Japan). The gas chromatograph was equipped with Rtx-5ms capillary column (Restek Corporation, USA) at 30m length, $0.25 \mathrm{~mm}$ internal diameter and $0.250 \mu \mathrm{m}$ thickness. The initial oven temperature was $150^{\circ} \mathrm{C}$, which was then ramped up by $8^{\circ} \mathrm{C} / \mathrm{min}$ to $190^{\circ} \mathrm{C}$ and maintained at $230^{\circ} \mathrm{C}$ for $18 \mathrm{~min}$. The injector and detector temperatures were
280 and $300^{\circ} \mathrm{C}$, respectively. Pressure was maintained at $100 \mathrm{KPa}$ and the solvent cut time used was $1.8 \mathrm{~min}$. Then $1 \mu \mathrm{l}$ of the prepared standard and sample were injected into the GC column using auto injection system. The gas Helium was used as the carrier with a flow rate of $1 \mathrm{ml} / \mathrm{min}$ and with a split mode at $1 / 30$. The methyl ester peaks were identified by the NIST11.LIB and NIST11S.LIB in mass spectrometry. The relative amount of each fatty acid methyl esters (FAME) was calculated from the integrated area of each peak and expressed as a percentage of the total area of all peaks using a capillary gas chromatograph equipped with a flame ionization detector (GC-FID 17A, Shimadzu, Kyoto, Japan) in the same conditions as described above.

\subsection{Statistical Analysis}

Data was expressed as mean values \pm standard deviations (SD) from at least two determinations. The statistical differences in the results were evaluated by student t-tests. The p-values $(<0.05)$ was considered to be significant.

\section{Results and Discussion}

\subsection{Oil Content}

The means for seed oil contents are shown in Figure 1. The oil concentration ranged in the first and second time of extraction from $62.95 \pm 0.24 \%$ to $61.11 \pm .18 \%$ (ecotype I) and $65.9 \pm 0.76 \%$ to $65.06 \pm 0.36 \%$ (ecotype II) respectively. The analysis of means and standard deviations revealed significant effects of ecotype on the oil content. The ecotype II had a higher oil content and were significantly different from those from ecotype I in the two times (D1 and D2) of oil extraction. However, the oil content of seeds from ecotype (I and II) in the two times of extraction is not significantly different. These results show that the oils content of $J$. curcas seeds depend on the ecotype.

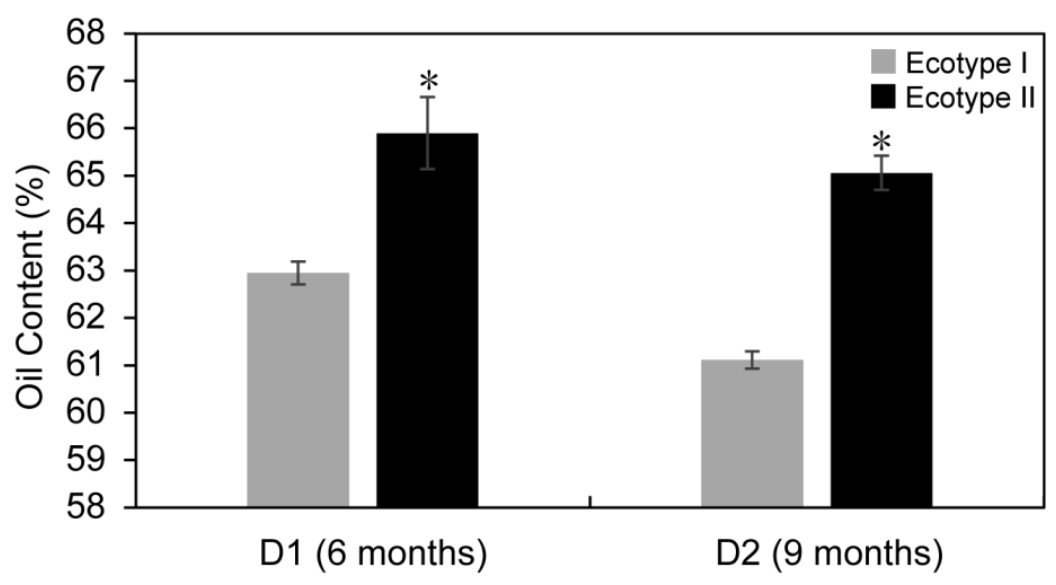

Storage time

Significant variability of oil content was detected for ecotype I during different seed storage times (i.e. D 1 and D 2) at the p-value $<0.05$. Similarly significant different was recorded for ecotype I and ecotype II at D1 stage, while highly significant different was recorded for ecotype I and ecotype II at D2 stage at the p-value $<0.01$.

Figure 1. Variation of Seeds oil content of two ecotypes of Jatropha curcas 
Rodrigues, Miranda [11] also found that the oil content of $J$. curcas seeds depends on their origin. The same result was reported from Barbosa, de Almeida-Cortez [12], that the oil content of Calotropis Proceravaried had something to do with the geographical distribution.

In our study, we found that the oil content was $65.9 \%$, higher compared to $35.18 \%$ of the work carried out by Rathbauer, Sonnleitner [5] in J. curcas seed from Mali.Verma and Verma [3] found that the biotype Rajasthan of $J$. curcas has the highest oil yield (42\%). Nzikou, Matos [13], reported a $48.5 \%$ yield by weight of the seed of $J$. curcas. The same authors found that the different variation in oil yield may be due to the differences in variety of plants, cultivation climate and the harvesting time of the seeds.

According to Sousa Barros, Castro Arriel [14], the oil content of $J$. curcas (35.0\%) was higher than Jatropha mollissima (18.3\%) and Jatropha gossypiifolia (22.1\%). The presence of high oil content in Jatropha seeds can give it special attention as biodiesel source [15].

According to Patel Shivani, Patel Khushbu [16] the soxhlet extraction method using hexane as organic solvent gave more oil yields than other extraction methods. The authors found the yielded oil to be in the range of $78 \%$. This method is better, may be because the process is continuous and there is complete oil recovery.

\subsection{Fatty Acids Composition}

According to Table 1 and Table 2, the fatty acids in seed oil of J. curcas crops are 14-25 carbon in length and contain 0-2 double bonds. Palmitoleic acid (C16:1) Palmitic acid (C16:0), linoleic acid (C18:2), oleic acid (C18:1), and Stearic acid (C18:0) were predominant in the seed oil of J. curcas from Mali. Among these, Saturated and unsaturated fatty acids were obtained with a predominance of unsaturated fatty acids, Wang, Lin [17] also fund the higher amount of unsaturated fatty acid $(80.93 \%, 79.53 \%, 77.24 \%$ and $78.22 \%)$ for the seed oils from Guangdong, Hainan, Guizhou and India, respectively.

The relative standard deviation values among of the two measurement results are also tabulated in Table 1 and Table 2. The oil from ecotype I presented the highest content of linoleic acid (37.27\%), oleic acid (32.46\%) in D1 which was significantly different from the contents found in D2.in this study, from Table 1, the ratio oleic/linoleic $(\mathrm{O} / \mathrm{L})$ was found to be $0.87 \%$ in $\mathrm{D} 1$ and increased in D2 to reach $1.22 \%$. Thus, Jatropha seed oil can be classified as an oleic-linoleic oil, and has been found useful for some manufacture of soap and in cosmetic industry [18]. This ratio with a high level of oleic acid (monounsaturated fatty acid) may have an excellent effect on biodiesel properties.[19].The higher amount of monounsaturated fatty acids is better for biodiesel feedstock than polyunsaturated fatty acids [15].

One of the most important elements of biodiesel properties is an oxidation stability of fatty acid methyl esters. Some studies showed that the fatty acid composition have direct effect on biodiesel properties. The higher contain of polyunsaturated fatty acids leads to poorer oxidation stability. This Oxidative stability is influenced by different factors such as fatty acid compound structural (number and position of the double bonds) and the presence of air [20,21,22]. For all fatty acids of Jatropha seed oils, there was no significant difference found in the oil content of ecotype I and II in the two periods of storage (D1, D2), except the content of Stearic acid found in D1 (11.20\% to $11.49 \%)$.

Table 1. Variation in fatty acids composition of Ecotype I

\begin{tabular}{|c|c|c|c|c|c|c|}
\hline \multirow[b]{2}{*}{ Fatty acids } & \multirow[b]{2}{*}{ Chemical formula } & \multirow[b]{2}{*}{ Acronym } & \multicolumn{2}{|c|}{ Date 1} & \multicolumn{2}{|c|}{ Date 2} \\
\hline & & & Composition $\%$ & Retention Time & Composition $\%$ & Retention Time \\
\hline Myristoleic acid & $\mathrm{C}_{14} \mathrm{H}_{26} \mathrm{O}_{2}$ & $\mathrm{C}_{14}: 1$ & - & - & $0.01 \pm 0$ & $8.70 \pm 0.01$ \\
\hline Pentadecanoic acid & $\mathrm{C}_{15} \mathrm{H}_{30} \mathrm{O}_{2}$ & $\mathrm{C}_{15}: 0$ & $0.03 \pm 0.01$ & $10.35 \pm 0.01$ & $0.03 \pm 0.01$ & $10.34 \pm 0.01$ \\
\hline Palmitoleic acid & $\mathrm{C}_{16} \mathrm{H}_{30} \mathrm{O}_{2}$ & $\mathrm{C}_{16}: 1$ & $1.66 \pm 0.14$ & $11.41 \pm 0.01$ & $1.78 \pm 0.13$ & $11.40 \pm 0.01$ \\
\hline Palmitic acid & $\mathrm{C}_{16} \mathrm{H}_{30} \mathrm{O}_{2}$ & $\mathrm{C}_{16}: 0$ & $15.74 \pm 0.14$ & $11.76 \pm 0.02$ & $16.59 \pm 0.30$ & $11.73 \pm 0.01$ \\
\hline Hexadecenoic acid & $\mathrm{C}_{17} \mathrm{H}_{32} \mathrm{O} 2$ & $\mathrm{C}_{17}: 1$ & $0.11 \pm 0.01$ & $12.77 \pm 0.01$ & $0.09 \pm 0.01$ & $12.76 \pm 0.01$ \\
\hline Heptadecanoic acid & $\mathrm{C}_{17} \mathrm{H}_{34} \mathrm{O} 2$ & $\mathrm{C}_{17}: 0$ & $0.19 \pm 0.03$ & $13.11 \pm 0.01$ & $0.17 \pm 0.01$ & $13.10 \pm 0.01$ \\
\hline Linoleic acid** & $\mathrm{C}_{18} \mathrm{H}_{32} \mathrm{O}_{2}$ & $\mathrm{C}_{18}: 2$ & $37.27 \pm 0.21$ & $14.22 \pm 0.05$ & $30.83 \pm 0.65$ & $14.16 \pm 0.01$ \\
\hline Oleic acid $* *$ & $\mathrm{C}_{18} \mathrm{H}_{34} \mathrm{O}_{2}$ & $\mathrm{C}_{18}: 1$ & $32.46 \pm 0.68$ & $14.36 \pm 0.05$ & $37.66 \pm 0.03$ & $14.30 \pm 0.01$ \\
\hline Stearic acid & $\mathrm{C}_{18} \mathrm{H}_{36} \mathrm{O}_{2}$ & $\mathrm{C}_{18}: 0$ & $11.20 \pm 0.02$ & $14.64 \pm 0.03$ & $11.52 \pm 0.22$ & $14.61 \pm 0.01$ \\
\hline Eicosenoic acid & $\mathrm{C}_{20} \mathrm{H}_{38} \mathrm{O}_{2}$ & $\mathrm{C}_{20}: 1$ & $0.19 \pm 0.04$ & $17.19 \pm 0.01$ & $0.17 \pm 0.02$ & $17.17 \pm 0.01$ \\
\hline Behenic acid & $\mathrm{C}_{22} \mathrm{H}_{44} \mathrm{O}_{2}$ & $\mathrm{C}_{22}: 0$ & $0.06 \pm 0.01$ & $20.60 \pm 0.01$ & $0.06 \pm 0.00$ & $20.59 \pm 0.01$ \\
\hline Tricosanoic acid & $\mathrm{C}_{23} \mathrm{H}_{46} \mathrm{O}_{2}$ & $\mathrm{C}_{23}: 0$ & $0.02 \pm 0.01$ & $22.34 \pm 0.01$ & $0.02 \pm 0.01$ & $22.33 \pm 0.01$ \\
\hline Lignoceric acid & $\mathrm{C}_{24} \mathrm{H}_{48} \mathrm{O}_{2}$ & $\mathrm{C}_{24}: 0$ & $0.08 \pm 0.02$ & $23.56 \pm 0.00$ & $0.07 \pm 0.01$ & $23.56 \pm 0.01$ \\
\hline Pentacosanoic acid & $\mathrm{C}_{25} \mathrm{H}_{50} \mathrm{O}_{2}$ & $\mathrm{C}_{25}: 0$ & $0.03 \pm 0.01$ & $24.67 \pm 0.00$ & $0.03 \pm 0.01$ & $24.65 \pm 0.01$ \\
\hline SFA & & & $27.94 \pm 0.32$ & & $29.06 \pm 0.58$ & \\
\hline UFA & & & $71.69 \pm 0.28$ & & $70.52 \pm 0.54$ & \\
\hline Others & & & $0.38 \pm 0.04$ & & $0.42 \pm 0.04$ & \\
\hline $\mathrm{O} / \mathrm{L}$ & & & $0.87 \pm 0.02$ & & $1.22 \pm 0.02$ & \\
\hline
\end{tabular}

Note: Fatty acid followed by $* *$ showed significant difference in fatty acid composition at the p-value $<0.01$. SFA (Saturated Fatty Acids), UFA (Unsaturated Fatty Acids), O/L (Oleic/Linoleic). 
Table 2. Variation in fatty acids composition of Ecotype

\begin{tabular}{|c|c|c|c|c|c|c|}
\hline \multirow[b]{2}{*}{ Fatty acids } & \multirow[b]{2}{*}{ Chemical formula } & \multirow[b]{2}{*}{ Acronym } & \multicolumn{2}{|c|}{ Date 1} & \multicolumn{2}{|c|}{ Date 2} \\
\hline & & & Composition \% & Retention Time & Composition \% & Retention Time \\
\hline Myristic acid & $\mathrm{C}_{14} \mathrm{H}_{28} \mathrm{O}_{2}$ & $\mathrm{C}_{14}: 0$ & $0.10 \pm 0.01$ & $9.05 \pm 0.01$ & $0.11 \pm 0.01$ & $9.04 \pm 0.00$ \\
\hline Pentadecanoic acid & $\mathrm{C}_{15} \mathrm{H}_{30} \mathrm{O}_{2}$ & $\mathrm{C}_{15}: 0$ & $0.02 \pm 0.00$ & $10.35 \pm 0.01$ & $0.02 \pm 0.00$ & $10.34 \pm 0.00$ \\
\hline Palmitoleic acid & $\mathrm{C}_{16} \mathrm{H}_{30} \mathrm{O}_{2}$ & $\mathrm{C}_{16}: 1$ & $1.71 \pm 0.11$ & $11.41 \pm 0.02$ & $1.82 \pm 0.17$ & $11.40 \pm 0.00$ \\
\hline Palmitic acid & $\mathrm{C}_{16} \mathrm{H}_{30} \mathrm{O}_{2}$ & $\mathrm{C}_{16}: 0$ & $15.81 \pm 0.20$ & $11.76 \pm 0.03$ & $16.34 \pm 0.39$ & $11.73 \pm 0.01$ \\
\hline Hexadecenoic acid & $\mathrm{C}_{17} \mathrm{H}_{32} \mathrm{O} 2$ & $\mathrm{C}_{17}: 1$ & $0.10 \pm 0.01$ & $12.77 \pm 0.01$ & $0.10 \pm 0.01$ & $12.72 \pm 0.00$ \\
\hline Heptadecanoic acid & $\mathrm{C}_{17} \mathrm{H}_{34} \mathrm{O} 2$ & $\mathrm{C}_{17}: 0$ & $0.17 \pm 0.01$ & $13.11 \pm 0.01$ & $0.18 \pm 0.01$ & $13.10 \pm 0.01$ \\
\hline Linoleic acid & $\mathrm{C}_{18} \mathrm{H}_{32} \mathrm{O}_{2}$ & $\mathrm{C}_{18}: 2$ & $38.02 \pm 1.17$ & $14.22 \pm 1.07$ & $32.26 \pm 2.29$ & $14.17 \pm 0.02$ \\
\hline Oleic acid* & $\mathrm{C}_{18} \mathrm{H}_{34} \mathrm{O}_{2}$ & $\mathrm{C}_{18}: 1$ & $31.28 \pm 1.17$ & $14.36 \pm 1.06$ & $36.31 \pm 0.84$ & $14.31 \pm 0.03$ \\
\hline Stearic acid & $\mathrm{C}_{18} \mathrm{H}_{36} \mathrm{O}_{2}$ & $\mathrm{C}_{18}: 0$ & $11.49 \pm 0.07$ & $14.65 \pm 0.04$ & $11.78 \pm 0.46$ & $14.61 \pm 0.02$ \\
\hline Eicosenoic acid & $\mathrm{C}_{20} \mathrm{H}_{38} \mathrm{O}_{2}$ & $\mathrm{C}_{20}: 1$ & $0.20 \pm 0.01$ & $17.19 \pm 0.01$ & $0.20 \pm 0.01$ & $17.17 \pm 0.01$ \\
\hline Arachidic acid & $\mathrm{C}_{20} \mathrm{H}_{40} \mathrm{O}_{2}$ & $\mathrm{C}_{20}: 0$ & $0.49 \pm 0.06$ & $17.59 \pm 0.01$ & $0.49 \pm 0.04$ & $17.57 \pm 0.01$ \\
\hline Behenic acid & $\mathrm{C}_{22} \mathrm{H}_{44} \mathrm{O}_{2}$ & $\mathrm{C}_{22}: 0$ & $0.06 \pm 0.01$ & $20.60 \pm 0.01$ & $0.07 \pm 0.01$ & $20.59 \pm 0.01$ \\
\hline Tricosanoic acid & $\mathrm{C}_{23} \mathrm{H}_{46} \mathrm{O}_{2}$ & $\mathrm{C}_{23}: 0$ & $0.01 \pm 0.01$ & - & $0.02 \pm 0.00$ & $22.33 \pm 0.01$ \\
\hline Lignoceric acid & $\mathrm{C}_{24} \mathrm{H}_{48} \mathrm{O}_{2}$ & $\mathrm{C}_{24}: 0$ & $0.07 \pm 0.01$ & $23.57 \pm 0.01$ & $0.07 \pm 0.01$ & $23.56 \pm 0.01$ \\
\hline Pentacosanoic acid & $\mathrm{C}_{25} \mathrm{H}_{50} \mathrm{O}_{2}$ & $\mathrm{C}_{25}: 0$ & $0.02 \pm 0.01$ & $24.67 \pm 0.01$ & $0.03 \pm 0.01$ & $24.65 \pm 0.01$ \\
\hline SFA & & & $28.23 \pm 0.01$ & & $29.08 \pm 0.93$ & \\
\hline UFA & & & $71.30 \pm 0.13$ & & $70.68 \pm 1.27$ & \\
\hline Others & & & $0.47 \pm 0.12$ & & $0.24 \pm 0.35$ & \\
\hline $\mathrm{O} / \mathrm{L}$ & & & $0.82 \pm 0.06$ & & $1.13 \pm 0.11$ & \\
\hline
\end{tabular}

Note: Fatty acid followed by * showed significant difference in fatty acid composition at the p-value $<0.05$.

SFA (Saturated Fatty Acids), UFA (Unsaturated Fatty Acids), O/L (Oleic/Linoleic).

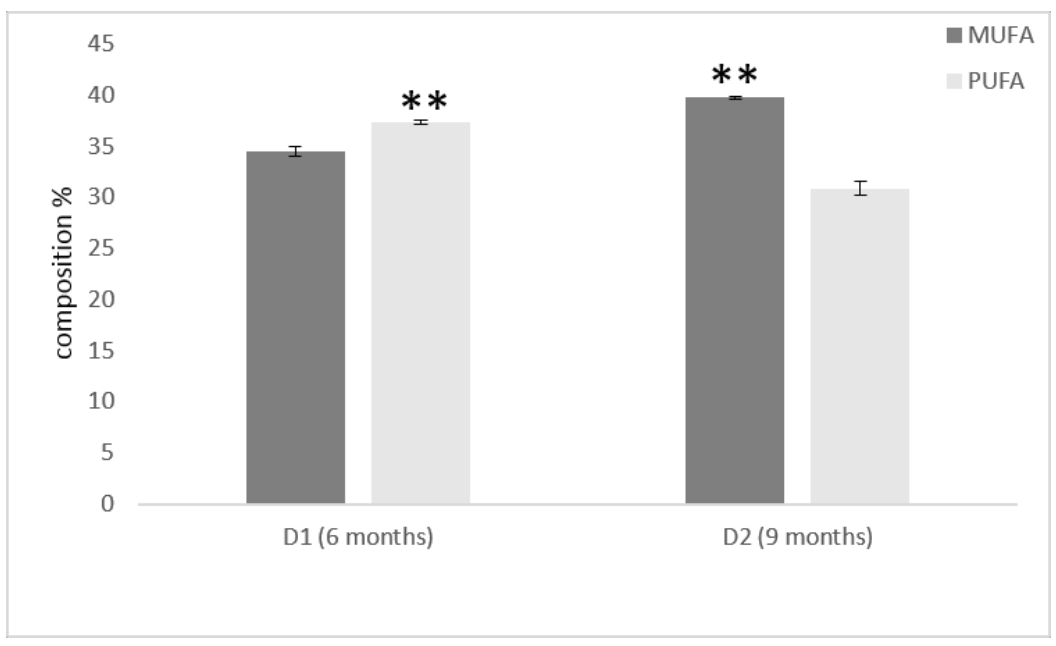

MUFA (monounsaturated fatty acid), PUFA (polyunsaturated fatty acid). Highly significant difference of monounsaturated and polyunsaturated fatty acid composition in D1 and D2 was detected during seed storage at the $\mathrm{p}$-value $<0.01$.

Figure 2. Variation of unsaturated fatty acid composition of ecotype I.

The seed oil from the ecotype I and II has shown in D1 a higher amount of unsaturated acids $(71.69 \%, 71.30 \%)$ than (D2) the second period of storage $(70.52 \%, 70.68 \%)$ respectively. The opposite effect was found for the saturated acids, the seed oil from the ecotype I and II has shown in D1 a lower amount $(27.94 \%, 29.06 \%)$ than (D2) the second time of storage $(28.23 \%, 29.08 \%)$ respectively.

When evaluating fatty acid composition for the treatment of D1 and D2, there was an increase in the percentage of saturated acids and monounsaturated fatty acids and decrease of polyunsaturated fatty acids for the ecotype I and ecotype II respectively (Figure 2, Figure 3). Akowuah, Addo [23] also fund that the free fatty acid content of $J$. curcas seed oils increases for the first and last month of storage with $7.83 \%$ to $32.10 \%$ respectively. The decrease in content of linoleic acids (polyunsaturated acid) during the storage periods may be due to its exposure to oxidation.

Due to its composition in fatty acids, the $J$. curcas oil from Teriyabugu (ecotype I) centre showed to be a good feedstock for biodiesel production than the oil from Katibougou center (ecotype II). 


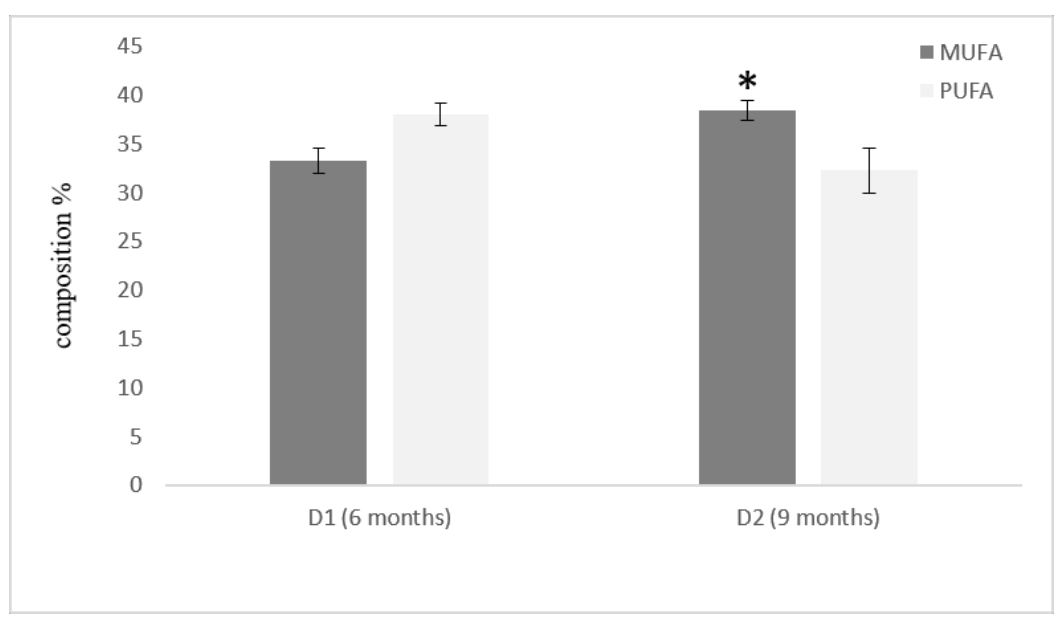

MUFA (monounsaturated fatty acid), PUFA (polyunsaturated fatty acid). The significant difference of unsaturated fatty acid composition was detected for MUFA during seed storage at the p-value $<0.05$

Figure 3. Variation of unsaturated fatty acid composition of ecotype II

For the first time, this study presents the comparison of oil content and composition of $J$. curcas from Katibougou and Teriyabugu ecological centers of Mali.

\section{Conclusion}

The seeds of $J$. curcas from Mali have in general a higher oil content. The ecotype II had the highest oil content and was significantly different from those from ecotype I in the two times (D1 and D2) of oil extraction. The essential fatty acid content of Malian $J$. curcas consists of Palmitoleic acid (C16:1) Palmitic acid (C16:0), linoleic acid (C18:2), oleic acid (C18:1), and Stearic acid (C18:0). The oil can be classified as an unsaturated oil $(70.52 \%$ to $71.69 \%)$ and an oleic-linoleic oil. The ratio oleic/linoleic $(\mathrm{O} / \mathrm{L})$ for the two ecotype was found to be $0.87 \%, 0.82 \%$ in D1 and increased for the second period in D2 to reach $1.22 \% .1 .13 \%$. The oil content of saturated and mono-unsaturated fatty acids had increased, and for polyunsaturated fatty acids had decreased. The analysis of means and standard deviations of the variation of oleic acid content revealed significant effects for the ecotype I in the two periods of seeds storage at $\mathrm{p}$-value $<0.05$. This investigation also revealed that the oil of the two ecotype of $J$. curcas contains high proportion of unsaturated fatty acids (oleic acid, linoleic acid). The highest amount of monounsaturated (mainly as oleic acid) fatty acid found in the seed oil of Malian $J$. curcas ecotype might give it an excellent effect on biodiesel properties and an application as a biodiesel feed stock.

\section{Acknowledgements}

The authors would like to thank the College of Biological Sciences and Biotechnology of Beijing Forestry University and the China Scholarship Council (CSC) for their technical and financial supports regarding this research. It is a pleasure to thank specially the Katibougou center and Teriya bugu center of Mali for their contribution.

\section{References}

[1] Richard, B. and L. NeBambi, "Jatropha: a small-holder bioenergy crop; the potential for pro-poor development". Integrated Crop Management. IFAD / FAO. , 2010, 8.

[2] Pratt J.H., Henry E.M.T., Mbeza H.F., Mlaka E. And S. L.B., Malawi Agroforestry Extension Project Marketing \& Enterprise Program Main Report, 2002. 118..

[3] Verma, K.C. and S.K. Verma, "Biophysicochemical Evaluation of Wild Hilly Biotypes of Jatropha curcas for Biodiesel Production and Micropropagation Study of Elite Plant Parts". Applied Biochemistry and Biotechnology, 2015, 175(1). 549-559.

[4] Liu, J., P. Chen, J. He, L. H. Deng, L. Y. Wang, J. D. Lei and L. Rong. "Extraction of oil from Jatropha curcas seeds by subcritical fluid extraction". Industrial Crops and Products, 2014, 62. 235-241.

[5] Rathbauer, J., A. Sonnleitner, R. Pirot, R. Zeller and D. Bacovsky. "Characterisation of Jatropha curcas seeds and oil from Mali". Biomass \& Bioenergy, 2012, 47. 201-210.

[6] Senou, H., Zheng, Cai X, Samake, G. Traore, M. B., Folega, F. and Traore, B. M. "Quantification of Seed Oil Content and Fatty Acid Profile of Jatropha curcas L. from Guizhou, China”. International Journal of Biology, 2016, 8(2). 92-97.

[7] Prankl, H. and H. Schindlbauer, "Oxidation Stability Of Fatty Acid Methyl Esters" in 10th European Conference on Biomass for Energy and Industry, BLT Würzburg: Germany, 1998, 5.

[8] Knothe, G., "Biodiesel and renewable diesel: A comparison." Progress in Energy and Combustion Science, 2010, 36(3). 364-373.

[9] Sahoo, P. K., L. M. Das, M. K. G. Babu, P. Arora, V. P. Singh, N. R. Kumar and T. S. Varyani. "Comparative evaluation of performance and emission characteristics of jatropha, karanja and polanga based biodiesel as fuel in a tractor engine". Fuel, 2009, 88(9). 1698-1707.

[10] Ong, H. C., T. M. I. Mahlia, H. H. Masjuki and R. S. Norhasyima. "Comparison of palm oil, Jatropha curcas and Calophyllum inophyllum for biodiesel: A review." Renewable and Sustainable Energy Reviews, 2011, 15(8). 3501-3515.

[11] Rodrigues, J., I. Miranda, J. Gominho, M. Vasconcelos, G. Barradas, H. Pereira, F. Bianchi-De-Aguiar and S. Ferreira-Dias. "Variability in oil content and composition and storage stability of seeds from Jatropha curcas L. grown in Mozambique". Industrial Crops and Products, 2013, 50. 828-837.

[12] Barbosa, M. O., J. S. De Almeida-Cortez, S. I. Da Silva and A. F. Morais De Oliveira. "Seed Oil Content and Fatty Acid Composition from Different Populations of Calotropis procera (Aiton) W. T. Aiton (Apocynaceae)". Journal of the American Oil Chemists Society, 2014, 91(8). 1433-1441.

[13] Nzikou, J. M., L. Matos, F. Mbemba, C. B. Ndangui, N. P. G. Pambou-Tobi, A. Kimbonguila, T. Silou, M. Linder and V. Desobry "Characteristics and Composition of Jatropha curcas Oils, 
Variety Congo-Brazzaville". Research Journal of Applied Sciences, Engineering and Technology, 2009, 1(3). 154-159.

[14] Sousa Barros, T. F., N. H. Castro Arriel, M. F. Queiroz, P. D Fernandes, S. Mendonca, J. A. Aquino Ribeiro and E. P. Medeiros "Fatty acid profiles of species of Jatropha curcas L., Jatropha mollissima (Pohl) Baill. and Jatropha gossypiifolia L". Industrial Crops and Products, 2015, 73. 106-108.

[15] Emil, A., Z. Yaakob, M. N. S. Kumar, J. M. Jahim and J. Salimon "Comparative Evaluation of Physicochemical Properties of Jatropha Seed Oil from Malaysia, Indonesia and Thailand". Journal of the American Oil Chemists Society, 2010, 87(6). 689-695.

[16] Shivani, P., P. Khushbu, N. Faldu, V. Thakkar and R. B. Shubramanian "Extraction and analysis of Jatropha curcas L. seed oil”. Bc'African Journal of Biotechnology, 2011, 10(79). 1821018213.

[17] Wang, Z.Y., J.M. Lin, and Z.F. Xu, "Oil contents and fatty acid composition in Jatropha curcas seeds collected from different regions". Nan Fang Yi Ke Da Xue Xue Bao, 2008, 28(6). 1045-6.

[18] Akbar E, Yaakob Z, Kamarudin Sk, Ismail M and S. J "Characteristic and composition of Jatropha curcas oil seed from
Malaysia and its potential as biodiesel feedstock feedstock". European Journal of Scientific Research, 2009, 29(3). 396-403.

[19] Pinzi, S., P. Rounce, J. M. Herreros, A. Tsolakis and M. Pilar Dorado "The effect of biodiesel fatty acid composition on combustion and diesel engine exhaust emissions". Fuel, 2013, 104 170-182.

[20] Knothe, G., "Structure indices in FA chemistry. How relevant is the iodine value?" Journal of the American Oil Chemists' Society, 2002, 79(9). 847-854.

[21] Hoekman, S. K., A. Broch, C. Robbins, E. Ceniceros and M. Natarajan "Review of biodiesel composition, properties, and specifications". Renewable and Sustainable Energy Reviews, 2012, 16(1). 143-169.

[22] Silitonga, A. S., H. H. Masjuki, T. M. I. Mahlia, H. C. Ong, W. T. Chong and M. H. Boosroh. "Overview properties of biodiesel diesel blends from edible and non-edible feedstock". Renewable \& Sustainable Energy Reviews. 2013, 22. 346-360.

[23] Akowuah, J.O., A. Addo, and F. Kemausuor, "Influence of Storage Duration of Jatropha Curcas Seed on Oil Yield and Free Fatty Acid Content”. ARPN Journal of Agricultural and Biological Science. 2012, 7(1). 41-45. 